\title{
Prevalence of Fascioliasis in Cattle Slaughtered in Sokoto Metropolitan Abattoir, Sokoto, Nigeria
}

\author{
A. A. Magaji, ${ }^{1}$ Kabir Ibrahim, ${ }^{2}$ M. D. Salihu, ${ }^{1}$ M. A. Saulawa, ${ }^{3}$ \\ A. A. Mohammed, ${ }^{4}$ and A. I. Musawa ${ }^{1}$ \\ ${ }^{1}$ Department of Veterinary Public Health and Preventive Medicine, Usmanu Danfodiyo University, PMB 2346, Sokoto, Nigeria \\ ${ }^{2}$ Faculty of Veterinary Medicine, Usmanu Danfodiyo University, PMB 2346, Sokoto, Nigeria \\ ${ }^{3}$ Veterinary Council of Nigeria, Maitama, Abuja, Nigeria \\ ${ }^{4}$ Department of Veterinary Parasitology and Entomology, Usmanu Danfodiyo University, PMB 2346, Sokoto, Nigeria
}

Correspondence should be addressed to A. A. Magaji; magaji1965@yahoo.com

Received 19 June 2014; Revised 2 October 2014; Accepted 17 October 2014; Published 9 November 2014

Academic Editor: Toru Mori

Copyright (C) 2014 A. A. Magaji et al. This is an open access article distributed under the Creative Commons Attribution License, which permits unrestricted use, distribution, and reproduction in any medium, provided the original work is properly cited.

\begin{abstract}
The prevalence of fascioliasis in cattle slaughtered in the Sokoto metropolitan abattoir was investigated. Faeces and bile samples were collected and processed using formal ether concentration technique. Gross lesions from 224 out of 1,313 slaughtered cattle were randomly selected and examined. Out of the 224 cattle examined, 95 (42.41\%) were males and 129 (57.59\%) were females. Out of 95 male cattle examined, 27 (28.42\%) were infected and out of 129 females 35 (27.13\%) were infected. Based on breed, infection rates were 31 (31.0\%), and 31 (25.2\%) for breeds of Sokoto Gudali and Red Bororo respectively. No infection was recorded in White Fulani breed. Lesions observed were more in males than in females and more in Red Bororo than in Sokoto Gudali. Overall, prevalence of infection with Fasciola was $27.68 \%$. There was no statistically significant association between infection and breed and between infection and sex of the animals sampled $(P>0.05)$. Regular treatment of all animals with an effective flukicide, as well as snail habitat control, tracing source of animals, public enlightenment about the disease, proper abattoir inspection, adequate and clean water supply to animals, and payment of compensation of condemned tissues and organs infested with the parasite by government were suggested.
\end{abstract}

\section{Introduction}

Fascioliasis, a serious infectious parasitic disease infecting domestic ruminants and humans, tops all the zoonotic helminthes worldwide [1]. A large variety of animals, such as sheep, goats, cattle, buffalo, horses, donkeys, camels and, rabbits, show infection rates that may reach $90 \%$ in some areas [2]. According to a World Health Organization (WHO) report in 2007 [3], the infection was limited in the past to specific and typical geographical areas (endemiotopes) but is now widespread throughout the world, with human cases being increasingly reported from Europe, the Americas, and Oceania (where only $F$. hepatica is transmitted) and from Africa and Asia (where the two species overlap). Fascioliasis is endemic in 61 countries and has become a food-borne infection of public health importance in parts of the world such as the Andean Highlands of Bolivia, Ecuador, and Peru; the Nile Delta of Egypt; and Northern Iran. It is estimated that more than 180 million people are at risk of infection, and infection rates are high enough to make fascioliasis a serious public health concern [4].

Bovine fasciolosis is a parasitic disease of cattle caused by trematodes usually Fasciola gigantica and rarely Fasciola hepatica in the tropics. The life cycle of these trematodes involves snail as an intermediate host [5]. The disease is usually characterized by a chronic, sometimes acute or subacute inflammation of the liver and bile ducts, accompanied by submandibular oedema, anaemia, anorexia, general intoxication, and death [6]. Meats infected by these organisms are regularly condemned at inspection in abattoirs/slaughter slabs. It could be zoonotic while constituting a major economic problem by lowering the productivity of cattle, in addition 
to losses from condemnation of affected organs. Humans can accidentally ingest the eggs/larvae and become infected [7]. Fasciolosis is enzootic in Nigeria and is of great economic importance especially in Northern Nigeria where stagnant water and fadamas are used as watering and grazing sites in the dry season. Fasciola gigantica is estimated to have diverged from $F$. hepatica approximately 17 million years ago [8] and penetrated more tropical regions in Asia and the Far East where it is the predominant parasitic disease of cattle and water buffalo [9]. Fasciola hepatica infects more than 300 million cattle and 250 million sheep worldwide and, together with $F$. gigantica, causes significant economic losses to global agriculture estimated to be more than US $\$ 3$ billion annually through lost productivity [10]. In West Africa, Nigeria precisely, important economic losses associated with fasciolosis are great expenses on anthelmintics for treatment; liver condemnation; production loss due to mortality; lower production of meat, milk, and wool; reduced weight gain; metabolic diseases and impaired fertility [11, 12]. The value of the losses resulting from this disease runs into millions of naira [6]. However, the estimation of economic losses due to fasciolosis at national and regional level is limited by lack of accurate estimation of prevalence of the disease [13]. Apart from direct economic losses associated with the disease, other nonquantifiable losses are also experienced.

The prevalence of fasciolosis in cattle in many parts of the world has been reviewed [14]. In Africa [14] quoted prevalence rates of $37 \%$ in Sudan, $45 \%$ in Cameroon, 30 90\% in Ethiopia, 16\% in Uganda, 62\% in the Central Africa Republic, and 50\% in Rwanda [15]. In Kenya, a retrospective study covering a period of 10 years (1990-1999) was carried out using postmortem meat inspection records [15]. A total of 5,421,188 cattle were slaughtered in the seven provinces of Kenya during the 10-year period and 427, 931 (8\%) of these cattle were infected with Fasciola. The region with the highest prevalence of fasciolosis was Western Province (16\%) followed, in descending order, by Eastern Province (11\%), Nyanza Province (9\%), Rift Valley Province (8\%), Central Province (6\%), Nairobi Province (4\%), and Coast Province (3.5\%). The total economic loss incurred by the country during the 10-year period as a result of condemnation of the infected livers was approximately US\$2.6 million [15].

In Nigeria, prevalence of fascioliasis has been reported from different parts of the country. There are also several reports on the prevalence, regional incidence, and seasonal variation for bovine fasciolosis [16, 17]. From slaughtered cattle in Maiduguri, Biu et al. [7] reported a prevalence of $80 \%$, from Zaria, Northwest, and a prevalence of $65.4 \%$ was also reported by [18]. A study was conducted to evaluate the number of cattle slaughtered, prevalence, seasonal variation, and socioeconomic consequence of bovine fasciolosis at the Ibadan municipal abattoir, Ibadan, Oyo State, Nigeria, between 1994 and 2004, based on retrospective abattoir meat inspection records and a perspective meat inspection survey [19]. Of the 1,640,095 cattle slaughtered in 11 years, 37,828 livers were condemned due to fasciolosis, translating into a prevalence of $2.31 \%$. The incidence observed among males 172 (4.24\%) was slightly higher than that noted for females 452 (3.73\%) though significant at 0.05 level of error. Moreover, the prevalence recorded in the dry season (October-March) was $19,816(2.58 \%)$ and $18,012(2.07 \%)$ for the rainy season (April-September) with a fairly strong positive correlation $(+0.76)$ occurring between the incidences of the disease in the seasons [18]. Another study was carried out between July and October 2012, aimed at determining the prevalence of fascioliasis and the economic loss of condemned liver due to Fasciola infection in cattle slaughtered at three abattoirs in Eket Urban, Akwa Ibom State, Nigeria [20]. A total of 279 cattle consisting of 185 males and 94 females were examined. The livers were examined for the adult flukes while the faecal samples were examined for the eggs of Fasciola. The result of the investigation showed that $38(13.62 \%)$ of the cattle were infected with fascioliasis. The prevalence rate recorded for female cattle was $17.02 \%$ compared to the male with prevalence rate of $11.89 \%$ [20].

This study would serve to recognize and appreciate the magnitude of problems and losses posed by fascioliasis and also fill the knowledge gaps (additional reference information) and update existing information on bovine fascioliasis in Sokoto State and Nigeria at large. This will eventually stimulate the interest to intensify efforts on its monitoring and surveillance towards the control and possible eradication of the disease in Nigeria.

\section{Materials and Methods}

2.1. Study Area. Sokoto State is geographically located at the North Western part of Nigeria between longitude $11^{\circ} 30^{\prime}$ to $13^{\circ} 50^{\prime}$ East and latitude $4^{\circ}$ to $6^{\circ} 40^{\prime}$ North. The state shares common borders with Niger Republic to the North, Kebbi State to the South, and Zamfara State to the East [21]. The state falls in the dry Sahel surrounded by sandy Sudan type Savannah [22].

The state, a major livestock producer lying in the arid region of the country, covers a total land area of about 32,000 square $\mathrm{km}$ with an estimated human population of $3,696,999$ million [21]. There are 23 local government areas in the state and the populace is predominantly farmers. Because of their sparse arable land, a good percentage of the populace is engaged in animal husbandry. The annual mean livestock population of the former Sokoto State (including Kebbi and Zamfara States which were carved out from the former Sokoto State in 1991 and 1996, resp.) for cattle was estimated to be $1,772,830\left(17,290\right.$ density/ $\left.\mathrm{km}^{2}\right), 2,466,484$ ( 24,055 density $\left./ \mathrm{km}^{2}\right)$ for goats, 2,566,246 (25,028 density $\left./ \mathrm{km}^{2}\right)$ for sheep, 43,960 (0.429 density $\left./ \mathrm{km}^{2}\right)$ for camels, and 109,484 (1.068 density $\left./ \mathrm{km}^{2}\right)$ for dogs [22].

Rainfall starts late in April and ends early in September with a mean rainfall ranging between $500 \mathrm{~mm}$ and $1,300 \mathrm{~mm}$. There are 2 main seasons in the state, namely, wet and dry seasons. The dry season starts from October and lasts up to April and the wet season begins in most parts of the state in May and lasts up to September or October [22].

2.2. Sample Collection. The postmortem investigation was conducted within the month of July 2010, by randomly examining 224 out of 1,313 cattle slaughtered at the municipal abattoir, Sokoto. 
Faecal materials were collected into polythene bags directly from the rectum of each of the cattle being sampled after they have been slaughtered. Gloved hands were used in faecal sample collections. Bile of each of the cattle used for the study was also collected from the gall bladder. The samples (bile and faeces) per cattle were each placed in polythene bags and labeled for proper identification. The lesions and samples for corresponding cattle, as well as the breed, sex, were also recorded. Samples were preserved in a refrigerator and were processed within 24 hours.

\section{Sample Processing}

3.1. Faecal Sample. Two grams (2 $\mathrm{g})$ of faeces was collected into labeled test tubes containing $3 \mathrm{mLs}$ of distilled water. The faecal samples and the distilled water were strained to give a suspension. The suspension was strained through a tea strainer into a corresponding cleaned labeled Petri dish. The filtrate was poured into corresponding test tubes. One milliliter $(1 \mathrm{~mL})$ of $10 \%$ formalin was added into the test tubes which were allowed to stand for 5 minutes. Diethyl-ether $(1 \mathrm{~mL})$ was added in the test tubes after 5 minutes, using different 18-gauge hypodermic needle and syringe. The test tubes containing the suspension were then corked, shaken to $\mathrm{mix}$, and centrifuged at $2000 \mathrm{rpm}$ for 8 minutes. The eggs and cysts of the parasites sediment at the bottom and the faecal debris became separated in a layer between the diethyl-ether and water. The supernatant was then decanted leaving few of it with the sediment. Drops (1-2) of the sediment were put on a glass slide, covered with cover slip, and viewed under microscope using $\times 100$ magnification.

3.2. Bile Sample. From the gall bladder, $2 \mathrm{~mL}$ of the bile was collected using 18-gauge hypodermic needle. The bile sample was then poured into a labeled test tube in a test tube rack. $1 \mathrm{~mL}$ of $10 \%$ formalin was added using 18 -gauge hypodermic needle and syringe into the bile sample and then allowed to stand for 5 minutes. Diethyl-ether $(1 \mathrm{~mL})$ was then added in the test tube after 5 minutes using a different 18-gauge hypodermic needle and syringe. The test tube containing the solution was then corked and shaken to mix the solution. The solution was then centrifuged at $2000 \mathrm{rpm}$ for 10 minutes. The eggs/cysts of the parasites sediment at the bottom of the mixture, while diethyl-ether with some fat comes up as supernatant. The supernatant was decanted leaving few of it with the sediment. Drops (1-2) of the sediment were put on a glass slide and covered with a cover slip and viewed under microscope using $\times 100$ magnification [23].

\section{Results}

Out of a total of 1,313 cattle slaughtered during the period of study, 224 were randomly selected. Out of the 224 sampled cattle, $62(27.68 \%)$ were infected. Ninety-five (95) of these were males with infection rate of $27(28.42 \%)$, while 129 were females with infection rate of 35 (27.13\%) (Table 1).

Out of 100 Sokoto Gudali breeds examined 31 (31\%) were infected, and out of 123 of Red Bororo breeds examined 31
TABLE 1: Prevalence of fascioliasis in cattle in relation to sex.

\begin{tabular}{lccc}
\hline & Infected & Not infected & Total \\
\hline Male & 27 & 68 & 95 \\
Female & 35 & 94 & 129 \\
Total & $\mathbf{6 2}$ & $\mathbf{1 6 2}$ & $\mathbf{2 2 4}$ \\
\hline
\end{tabular}

$\chi^{2}$ d.f. $=1 ; P=0.8312$.

TABLE 2: Prevalence of fascioliasis in relation to breeds.

\begin{tabular}{lccc}
\hline Breed & Infected & Not infected & Total \\
\hline SG & 31 & 69 & 100 \\
RB & 31 & 92 & 123 \\
WF & 0 & 1 & 1 \\
Total & $\mathbf{6 2}$ & $\mathbf{1 6 2}$ & $\mathbf{2 2 4}$ \\
\hline
\end{tabular}

S.G.: Sokoto Gudali, RB: Red Bororo, and WF: White Fulani.

$\chi^{2}$ d.f. $=2 ; P=0.5194$.

(25.2\%) were found infected, while 1 of White Fulani breed was free of the disease (Table 2).

Statistical analysis of the data revealed no statistically significant association $(P>0.05)$ between infection with the parasite and breed and sex of the sampled animals (Tables 1 and 2).

\section{Discussion}

The study has revealed the prevalence of fascioliasis in cattle slaughtered in the Sokoto metropolitan abattoir, Sokoto, Nigeria. Disease prevalence was found to be more in males than in females. This is in accordance with the findings of $[24,25]$. The infection was again more in Sokoto Gudali than in Red Bororo breed and the White Fulani breed of cattle.

The disparity in susceptibility to helminth infection between the 2 sexes could be attributed to the differences in the host intrinsic factors (genetics, physiology, and immunology) and extrinsic factors (environment and management practices). The lesions observed are more in males than in females and more common in Red Bororo than in Sokoto Gudali probably due to differences in the number of animals examined.

The prevalence of fascioliasis among cattle recorded in this research work can be attributed to the climatic conditions of this location which does not favour the survival of the intermediate hosts, the snail. This intermediate host prefers swampy areas with slowly moving water and small streams which also allow sufficient moisture for the survival of the infective metacercariae. In contrast, the study area, Sokoto, occupies low flat and naturally dry land (semiarid area). This probably explains the low percentage of infection with fascioliasis among cattle slaughtered in the abattoir.

The general picture of fascioliasis in the study area shows that there was no significant difference in infection between male and female cattle $(P>0.05)$. This is in sharp contrast with the studies earlier reported by [26, 27], who reported a higher infection rate among the male cattle than the female cattle from Gwagwalada abattoir, Federal Capital Territory, Abuja, Nigeria, and Jalingo abattoir, Taraba state, Nigeria, 
respectively. The possible explanation could be that both sexes move together in search of food and water and therefore possibility for both sexes to be equally exposed to the risk of infection is high [26].

\section{Conclusion}

The prevalence of fascioliasis in cattle revealed by this work highlights the infection as being more common in male than in female and more common in Sokoto Gudali breed than in Red Bororo breed of cattle, with no statistically significant difference between rate of infection in males and in females and also between breeds.

\section{Recommendations}

Given the reported prevalence of fascioliasis in Sokoto metropolitan abattoir, a control program in this region appeared justified. The following recommendations are advocated for effective control program: public enlightenment about the disease and the role of snails in the life cycle of the parasite as well as associated health risks in animals and humans; artificial pasture land (rangeland system) that seems to be a good panacea in control of the disease in cattle; development of well-defined interval for deworming of cattle, especially newly purchased ones with effective drugs such as albendazole and praziquantel; proper meat inspection (with appropriate compensation for condemned animals or their parts) that should be revisited and properly enforced; abattoir record keeping that should be reviewed to provide information on livestock diseases.

\section{Conflict of Interests}

The authors declare that there is no conflict of interests regarding the publication of this paper.

\section{References}

[1] F. M. Haridy, T. A. Morsy, N. I. Gawish, T. N. Antonios, and A. G. Abdel Gawad, "The potential reservoir role of donkeys and horses in zoonotic fascioliasis in Gharbia Governorate, Egypt," Journal of the Egyptian Society of Parasitology, vol. 32, no. 2, pp. 561-570, 2002.

[2] H. F. Farag, "Human fascioliasis in some countries of the Eastern Mediterranean Region," Eastern Mediterranean Health Journal, vol. 4, no. 1, pp. 156-160, 1998.

[3] WHO, "Report of the WHO Informal Meeting on use of triclabendazole in fascioliasis control," Tech. Rep. WHO/CDS/ NTD/PCT/2007.1, 2007.

[4] WHO, "Triclabendazole and fascioliasis-a new drug to combat an age-old disease," Fact Sheet no. 191, 1998.

[5] S. M. Walker, A. E. Makundi, F. V. Namuba et al., "The distribution of Fasciola hepatica and Fasciola gigantica within Southern Tanzania-constraints associated with the intermediate host," Parasitology, vol. 135, no. 4, pp. 495-503, 2008.

[6] A. Ogunrinade and B. I. Ogunrinade, "Economic importance of bovine fascioliasis in Nigeria," Tropical Animal Health and Production, vol. 12, no. 3, pp. 155-160, 1980.
[7] A. A. Biu, M. I. Ahmed, and S. S. Mshelia, "Economic assessment of losses due to parasitic diseases common at the Maiduguri abattoir, Nigeria," African Scientist, vol. 7, no. 3, pp. 143-145, 2006.

[8] J. A. Irving, T. W. Spithill, R. N. Pike, J. C. Whisstock, and P. M. Smooker, "The evolution of enzyme specificity in Fasciola spp," Journal of Molecular Evolution, vol. 57, no. 1, pp. 1-15, 2003.

[9] D. P. McManus and J. P. Dalton, "Vaccines against the zoonotic trematodes Schistosoma japonicum, Fasciola hepatica and Fasciola gigantica," Parasitology, vol. 133, no. 2, pp. S43-S61, 2006.

[10] S. Mas-Coma, M. D. Bargues, and M. A. Valero, "Fascioliasis and other plant-borne trematode zoonoses," International Journal for Parasitology, vol. 35, no. 11-12, pp. 1255-1278, 2005.

[11] S. M. T. Marques and M. L. Scroferneker, "Fasciola hepatica infection in cattle and buffaloes in the State of Rio Grande do Sul, Brazil," Parasitologia Latinoamericana, vol. 58, no. 3-4, pp. 169-172, 2003.

[12] C. Mason, "Fasciolosis associated with metabolic disease in a dairy herd, and its effects on health and productivity," Cattle Practice, vol. 12, no. 1, pp. 7-13, 2004.

[13] O. A. Adedokun, A. B. Ayinmode, and B. O. Fagbemi, "Seasonal prevalence of Fasciola gigantica infection among the sexes in Nigerian cattle," Veterinary Research, vol. 2, no. 1, pp. 12-14, 2008.

[14] J. P. Megard, Fasciolosis in Black Africa, Merck, Sharp \& Dohme Research Development, Paris, France, 1978.

[15] J. M. Kithuka, N. Maingi, F. M. Njeruh, and J. N. Ombui, “The prevalence and economic importance of bovine fasciolosis in Kenya-an analysis of abattoir data," Onderstepoort Journal of Veterinary Research, vol. 69, no. 4, pp. 255-262, 2002.

[16] D. A. Babalola and T. W. Schillhorn Van Veen, "Incidence of fascioliasis in cattle slaughtered in Bauchi (Nigeria)," Tropical Animal Health and Production, vol. 8, no. 4, pp. 243-247, 1976.

[17] J. Maurice, "Is something lurking in your liver?" New Scientist, vol. 141, no. 1917, pp. 26-31, 1994.

[18] T. W. Schillhorn Van Veen, D. O. B. Foloranmi, S. Usman, and T. Ishaya, "Incidence of liver fluke infections (Fasciola gigantica and Dicrocoelium Hospes) in ruminants in northern Nigeria," Tropical Animal Health and Production, vol. 12, no. 2, pp. 97$104,1980$.

[19] M. Oladele-Bukola and I. A. Odetokun, "Prevalence of Bovine Fasciolosis at the Ibadan Municipal Abattoir, Nigeria," African Journal of Food, Agriculture, Nutrition and Development, vol. 14, no. 4, pp. 9055-9070, 2014.

[20] L. P. E. Usip, E. S. Ibanga, H. J. Edoho, E. C. Amadi, and E. Utah, "Prevalence of Fascioliasis and the economic loss of condemned liver due to Fasciola infection in Cattle slaughtered at three abattoirs in Eket Urban, Akwa Ibom State of Nigeria," Global Advanced Research Journal of Food Science and Technology, vol. 3, no. 2, pp. 54-75, 2014.

[21] National Population Commission (NPC), Census Data of 2006.

[22] A. Bala, S. Nasiru, J. A. Usman et al., "Detection of lead (Pb), cadmium $(\mathrm{Cd})$, chromium $(\mathrm{Cr})$ nickel $(\mathrm{Ni})$ and magnesium residue in kidney and liver of slaughtered cattle in Sokoto Central Abattoir, Sokoto State, Nigeria," International Journal of Livestock Research, vol. 4, no. 1, pp. 74-80, 2014.

[23] M. Cheesbrough, District Laboratory Practice in Tropical Countries, part 1, Cambridge University press, Cambridge, UK, 1980.

[24] S. K. Mankau and R. Hamilton, "The effect of sex and sex hormones on the infection of rats by Trichinella spiralis," Canadian Journal of Zoology, vol. 50, no. 5, pp. 597-602, 1972. 
[25] J. J. Reddington, G. L. Stewart, G. W. Kramar, and M. A. Kramar, "The effects of host sex and hormones on Trichinella spiralis in the mouse," The Journal of Parasitology, vol. 67, no. 4, pp. 548$555,1981$.

[26] H. S. Idris and A. A. Madara, "Vector competence and prevalence of Fasciola gigantica in cattle slaughtered in Gwagwalada abattoir, Abuja, Nigeria," Biological and Environmental Science Journal for the Tropics, vol. 1, no. 2, pp. 48-52, 2005.

[27] S. E. Obadiah, "Preliminary studies on fascioliasis in cattle slaughtered at Jalingo abattoir, Taraba state, Nigeria," Nigerian Journal of Science, Technology and Environmental Education, vol. 3, no. 1, pp. 143-146, 2010. 


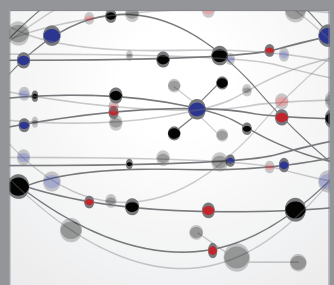

The Scientific World Journal
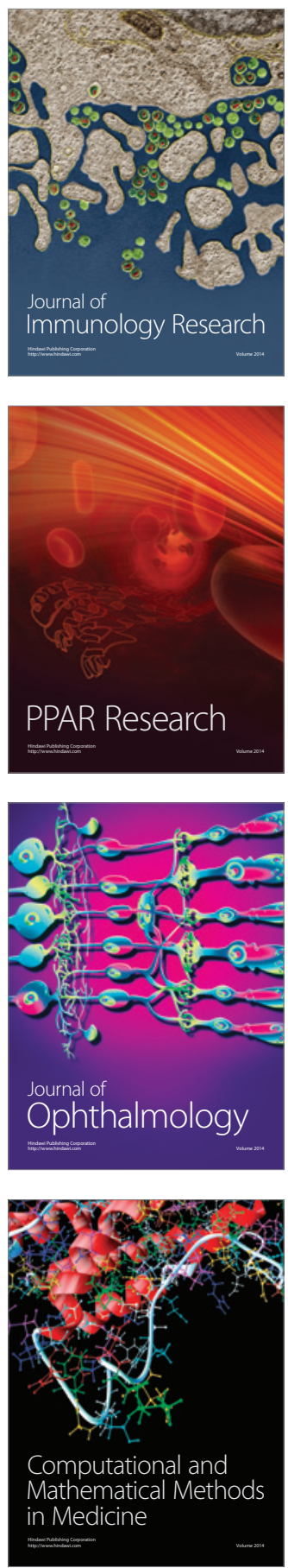

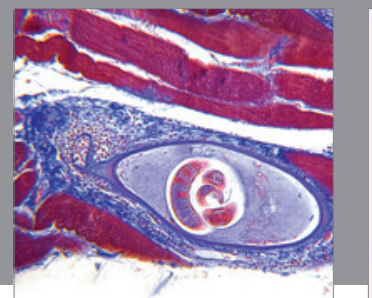

Gastroenterology

Research and Practice
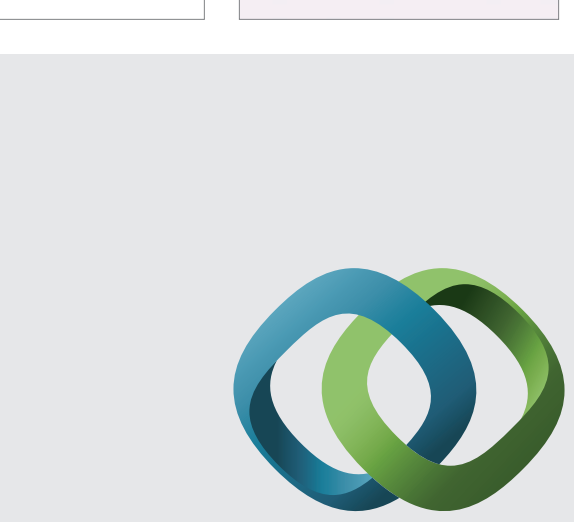

\section{Hindawi}

Submit your manuscripts at

http://www.hindawi.com
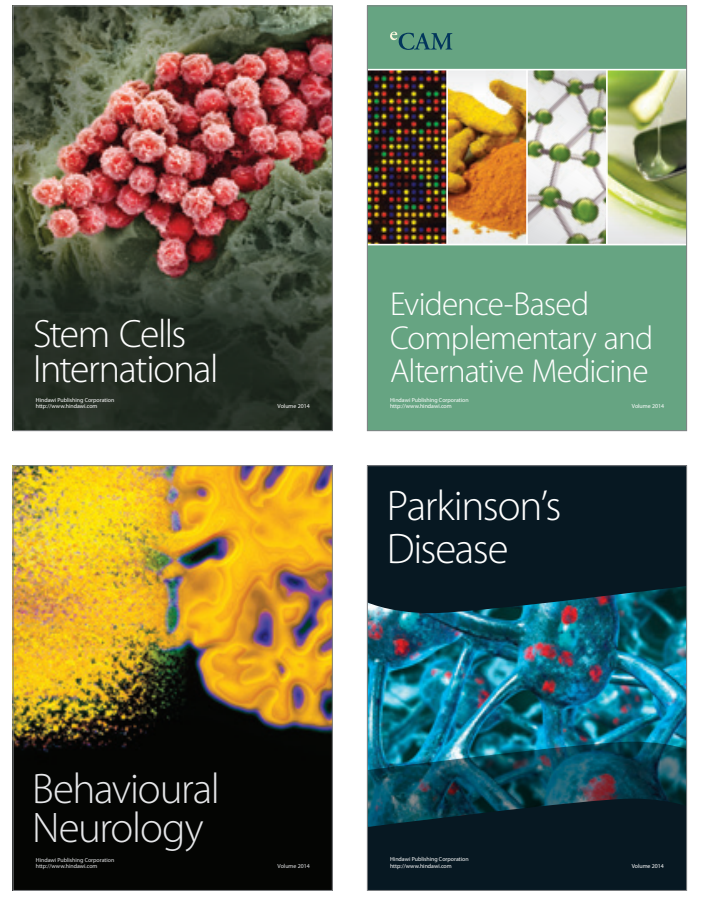
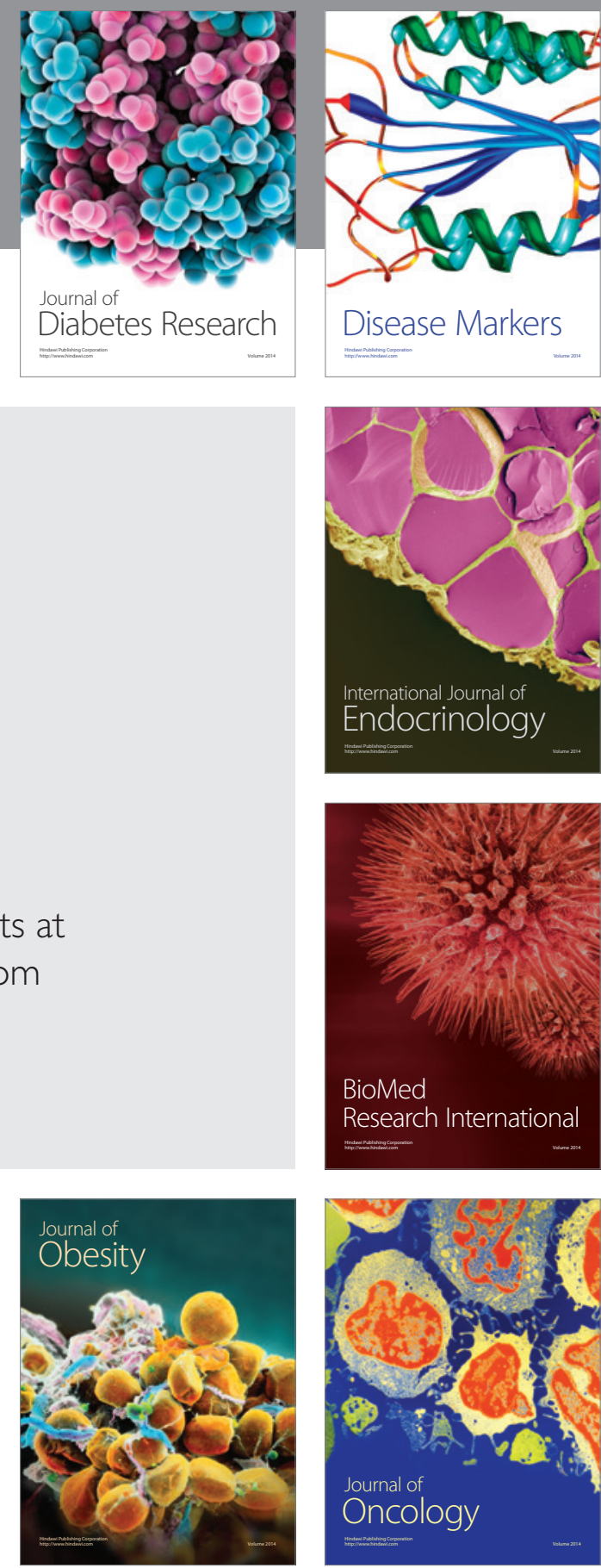

Disease Markers
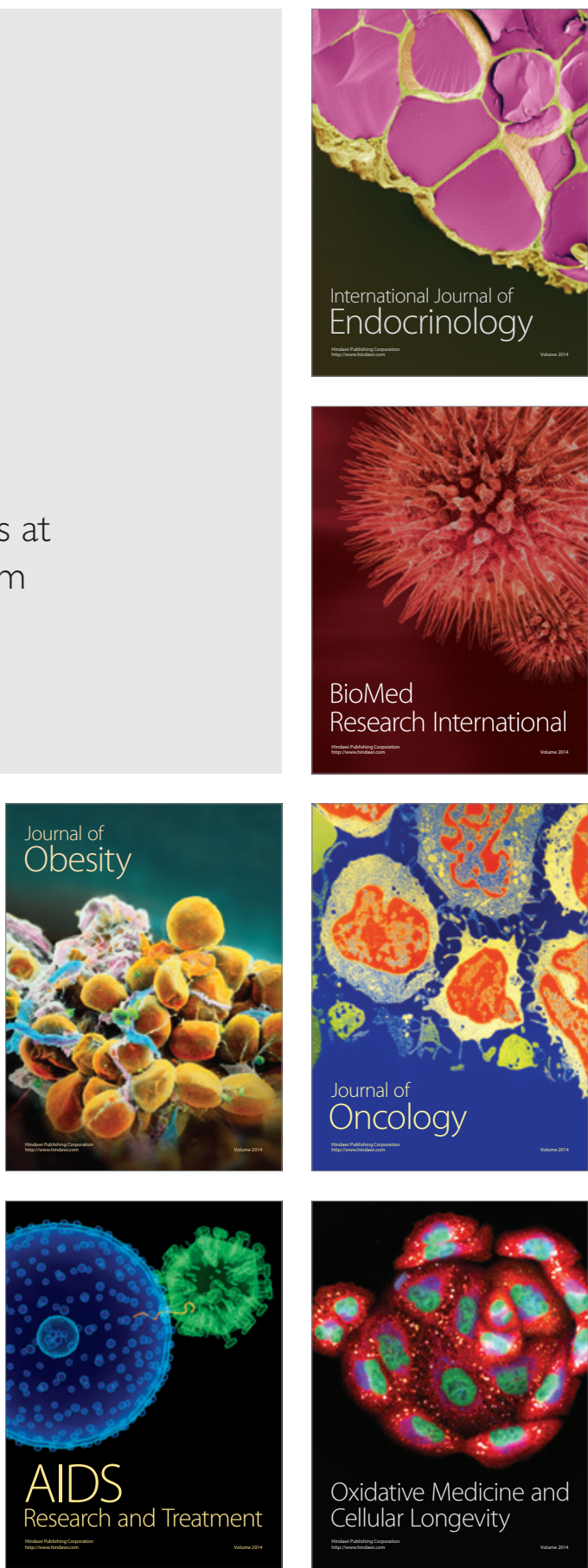